\title{
Free float and liquidity screening of the JSE
}

\author{
H. Andersen* \\ Financial Engineer, AIG South Africa, \\ Republic of South Africa \\ Hugh.Andersen@aig.com \\ F. Durand \\ Senior Lecturer, Head of Department of Informatics, Finance and Operations, \\ Wits Business School, University of Witwatersrand, \\ Johannesburg 2000, Republic of South Africa \\ Received September 2001
}

\begin{abstract}
Current index construction techniques screen potential index constituents in order to exclude those with a low liquidity and/or free float, the actual percentage of shares available for trade, to provide an improved performance benchmark.

Four techniques have been applied to the JSE to determine an optimum benchmark. Three indices were constructed using the Financial Times Securities Exchange, Dow Jones STOXX and Morgan Stanley Capital International screening rules. The fourth was constructed by developing new rules. The study found that investors experienced free float and liquidity constraints and that a JSE free float index is required. It also showed that the American and British rules did not provide an improved index and that new, more appropriate rules were needed to create an optimum free float index.
\end{abstract}

*To whom all correspondence should be addressed.

\section{Introduction}

The introduction of increasingly complex investment products has made performance evaluation difficult and has motivated a demand for improved performance benchmarks. Occurrences of 'window dressing' by overstating performance of the fund, or switching the fund into more fashionable equities immediately before a reporting date, both locally and internationally, have been evident (Lakonishok, Shleifer, Thaler \& Vishny, 1991; Gleason, 1998; Wood, 1999).

Despite problems with portfolio measurement, correct evaluation is important because it informs investors about the returns on their investments, determines manager remuneration and directs future investments (Ippoloito, 1992).

Current trends in index construction screen the 'investable universe', which is the set of stocks an investor can purchase shares from, in order to eliminate stocks with a low liquidity and free float, the actual percentage of shares available for trade (MSCI, 2000). The system of calculating indices on the JSE directly from market capitalisation, without regard to the liquidity or availability of the stocks, has been found to distort the market and alter the way in which investors view the market and it's sectors (McNulty, 2001). The JSE has confirmed its intention to introduce screening of index constituents in 2001 to eliminate those with a low free float.

The objective of this study is to determine if an index based on liquidity and free float screens would better represent the market than the All Share Index (C101). Several institutions have developed screening rules. Among the most popular are the Financial Times Securities Exchange All World Ground Rules (FTSE) (FTSE, 2000), Dow Jones STOXX Index Guide (STOXX, 2000) and those of the Morgan Stanley Capital International (MSCI) (MSCI, 2000).

Four indices were constructed. The first three indices were based on these three sets of screening rules and the fourth was constructed using parts of each of these sets of rules in an attempt to form an optimal index.

The suitability of the different screening rules was determined. This was done by establishing whether the new indices were a more effective benchmark for unit trusts investing in the general equity sector of JSE than the CI01; correlated with and out-performed the CI01 and more effectively represented stocks listed on the JSE than the CI01.

\section{Literature review}

\section{Portfolio performance evaluation}

Portfolio evaluation divides into two main categories: risk adjusted return methods, which involve calculating the risk adjusted return using a formula, and comparison methods which involve comparing the fund with other funds in the same sector or against an emerging, domestic or specialised benchmark. 


\section{Measurement of performance using risk adjusted returns}

The Sharpe, Modigliani-squared $\left(\mathrm{M}^{2}\right)$, Treynor, Jensen and Appraisal ratios all calculate the relative return of the fund adjusted by a measure of fund risk.

Although easy to calculate, these ratios suffer various problems.

- The risk measures differ between models so that funds can have different performance rankings for different models.

- $\quad$ The high variance of stock returns requires a very long observation period to determine performance levels with any statistical significance. In the majority of cases, funds have not been in operation for very long and in cases where they have there will have been several managers during that period, rendering manager assessment difficult.

- Performance measurements change when the portfolio composition is changed. For example, changing a portfolio's holdings will distort Sharpe's measure since changes in the mean return would increase the variance. Similarly the measures cannot be used to compare two differently constrained funds.

- The security characteristic line parameters used to calculate the risk adjusted return measure do not take market timing into account. As a result, a good market timer can be penalised for attempting to time the market.

- Rankings can be manipulated by 'window dressing' fund performance at the end of a quarter (Gleason, 1998; Wood, 1999).

- Ambiguities in assessing performance using risk adjusted performance measures can also be caused by borrowing and lending at different rates (Tucker, Becker, Isimbubi \& Ogden, 1994) and changes in a portfolio's beta, known as Roll's Critique. Roll (1978) observed that a portfolio's beta could change if different benchmark indices are chosen; for instance the Standard and Poor 500 or the Dow Jones Industrial Average, resulting in a different ranking if Treynor's or Jensen's methods are used.

\section{Measurement of performances by comparison of returns}

The second category of performance evaluation compares funds with other funds investing in the same universe, with an emerging market or domestic index or against a special index.

\section{Comparison with other funds}

This method groups funds according to the sector from which the fund manager selects stocks, for example the resources sector. The increase in the unit price of the fund is calculated for a three, six, twelve (on a sell-sell basis) and thirty-six month (on a buy-sell basis) period and is used to rank the funds against each other. The Financial Mail's section entitled Personal Wealth Weekly (2001) employs this method.

Limitations of this method include the lack of risk adjustment, the possibility of window dressing, and the exclusion of cash flow timing effects.

\section{Comparison with emerging market indices}

The major indices for this method include:

- International Finance Corporation Global;

- International Finance Corporation Investable;

- Morgan Stanley Capital International Emerging Markets Global;

- Morgan Stanley Capital International Emerging Market Free; and

\section{- $\quad$ ING Barings;}

Masters (1998) concludes that emerging market indices are poor benchmarks for measuring fund performance, as the indices are problematic, inefficient and produce different results.

\section{Comparison with domestic indices}

Four South African domestic indices were used as a benchmark for fund evaluation. These were the Plexus Unit Trust Indices, the MoneyMate benchmark, the JSE/Actuaries Indices and the HSBC Free Float Index. In addition, a specially developed normal portfolio or benchmark was used.

Three Plexus Unit Trust Indices were used. These were the All Equity Index, an All Asset Allocation Index and an All Fixed Interest Index to measure unit trust performance (Moneymax, 2000).

The MoneyMate Index was the average performance measure for the Domestic Equity, General Fund sector (Personal Finance, 2000). All funds in the sector carried equal weight and the MoneyMate Index tracked the average return.

The JSE/Actuaries Indices reflected the performance of the South African market. The CI01 measured the performance of the over-all market, whilst the sector indices measured the performance of companies in a particular sector (JSE, 2000). JSE/Actuaries Indices consist of ordinary securities weighted by their market capitalisation. For a larger company, the share price movement would have greater effect on the index than for a smaller company. For each index, the price index was defined as the index value calculated as the total market capitalisation divided by the 
index divisor, and is used as an investment benchmark. The index divisor, which is usually referred to as the k-factor or base value, was adjusted to keep the index value constant during new corporate actions that could affect the market capitalisation. These include share issues, mergers and unbundling and this restricted index changes to price movements only.

Gaymans (2001) developed the HSBC Free Float Index based on large capitalisation stocks listed on the JSE. The Index was weighted according to the free float market capitalisation and was adjusted using the MSCI weighting methodology.

The index was formulated by identifying a pool of securities from which the index constituents would be drawn. This pool, based on all securities listed on the JSE was screened, and securities removed if deemed inappropriate for inclusion. As a result, company debentures, preference shares and warrants were removed, leaving a 'universe' of stocks from which the index constituents could be selected. This universe was then ranked by market capitalisation on the last day of the month proceeding the rebalance date and the top 150 stocks were selected. These 150 stocks were then ranked in terms of turnover ratio for the past six months and illiquid stocks removed. The liquid stocks were then ranked by the average free float market capitalisation over the previous three months, and the top 50 stocks were selected to form the free float index. The free float of the liquid universe is determined manually by examination of the share registers.

Back tests of the index have shown it out-performed the ALSI 40 and CI01 by $30.43 \%$ and $41.02 \%$ respectively (Gaymans, 2001).

This index lacked the capacity for risk adjustment although, unlike the first three indices, liquidity and free float are taken into account. The construction method exposed the index to the effects of survivorship bias, which may have increased or decreased its performance. The small number of index constituents also made the index unsuitable as a measure of the market's overall performance.

Fabozzi (1989:382) defines a normal portfolio as 'a set of securities that contains all of the securities from which a manager normally chooses, weighted as the manager would weight them in a portfolio. As such, a normal portfolio is a specialised index'. The word 'normal' was included to capture the idea that for each manager, or class of managers, there exists a habitat of securities whose composition is similar to the manager's average portfolio over time. Evaluation of fund performance by way of comparison with a normal portfolio is more accurate than using a domestic index because it can take genuine market and fund constraints into account.

Bailey, Richards \& Tieney (1990) noted that the five characteristics for an optimal benchmark are the fact that their weightings are known ex-ante, they are investable, unambiguous, measurable and represent a fund manager's respective style.
Luck (1995) adds that, in addition, the benchmark's construction should be transparent, and its rules utilise published data and be clearly defined. However, as in the case of other indices, a normal portfolio is not risk adjusted and does not measure the ability to time the market. By definition, the use of normal portfolios is also limited to funds that select stocks from the same universe as that from which the normal portfolio is constructed. Kritzman (1987) and Good (1983) consider normal portfolios to be appropriate performance benchmarks because they adjust for management style and therefore provide a level against which a particular fund can be evaluated.

Although differences among the available US equity indices have been minor, no single major index may have the appropriate capitalisation and value-growth mixes to be suitable as a benchmark for a particular portfolio (Lummer, 1995). Good (1983) infers that normal portfolios allow the plan sponsor to have improved control of their total universe of funds by clearly defining the strategy of each of his fund managers. He also notes that the plan sponsor, and not individual fund managers, is responsible for the performance of the entire universe of funds (Good, 1984). Mossavar-Rahmani (1987) identifies four reasons for growing interest in customised benchmarks.

- Financial Accounting Standards Board Statements 87 and 88 , of the United States, prompted pension plan sponsors to link the expected return on assets more closely to particular liabilities. A risk adverse pension plan sponsor could use a customised benchmark to maintain stable or favourable asset-liability ratios.

- Investment advisors who adopt structured management enjoy established market niches by promoting their specific capabilities and services in designing and using customised benchmarks.

- Investment advisors can command higher fees for managing structured portfolios based on customised benchmarks than for those based on generic benchmarks.

- To capture greater markets share in index and indexrelated products. For example, Salomon Brothers introduced the Large Pension Fund Baseline Bond Index, which is a standardised customised benchmark, used specifically for large long-term pension funds.

Despite the advantages of normal portfolios, Grinold (1992) showed that four out of five benchmark portfolios are not ex ante efficient. However, he concludes that his results should be viewed as indicative but not conclusive, and therefore does not negate the benefits of normal portfolios. Cohen, Zinberg \& Zeikel (1987) observe growing use of normal portfolios to assess their performance for pension fund clients.

\section{Index construction}

Francis (1986) noted that a well-constructed index would give an indication of the entire population of stocks under 
consideration and suggests that in designing an index the following four characteristics should be considered.

- Sample size: The sample size should be a significant fraction of the population being studied.

- Representation: The sample should contain elements from all sections of the population, and should not exclude sections.

- Weighting: The index constituents should be assigned weights that correspond to the actual investment opportunities in the population under study.

- Convenient units: The index should be stated in units that are easy to understand and that could be used simply to answer research questions.

The constituents of stock market indices can be, priceweighted, market-value-weighted, equally weighted or weighted by the geometric averages of the index constituents. Market-value weighting has both advantages and disadvantages (Fabozzi, 1989). A market-value weighted normal portfolio does not need to be rebalanced because of fluctuations in the price of the stocks in the portfolio. Liquidity problems tend to be minimised because a fund purchases a varying percentage of each company that allows easier indexing. Although market-value weighting is beneficial, managers often do not capital weight their portfolios because of their aversion to investing too much money in one stock which is seen as equivalent to taking a bet on the stock. Market-value weighting also tends to weight some sectors of the market more than the average institutional fund manager does. However, weighting other than by market-value renders re-balancing difficult, and not all fund managers can adopt such portfolios.

\section{Survivorship bias}

The idea behind survivorship bias is that any portfolio of firms doing business today includes only those that have survived past travails. If a list of today's best investments is tracked back in time, it will inevitably be a good performer because it is biased to include only the survivors (Blitzer, 1995). When evaluating the historical performance of an index, survivorship bias can either make poor performance look good or understate performance, thus making a good strategy seem mediocre. However there is some disagreement on the direction (Blitzer, 1995; Garcia \& Gould, 1993).

The effects of survivorship bias can be negated by the inclusion of all listed stocks in the index at the time the index value is calculated.

\section{Research hypothesis, proposition and question}

One research question, one proposition and one hypothesis were identified.

\section{Research question}

Does the application of any of the four screening rules to stocks listed on the JSE result in a more representative index of the JSE than the CI01?

\section{Proposition}

The proposition proposed that the Sharpe measure for one of the normal portfolios would out-perform the CI01's Sharpe measure during the period January 1996 to December 2000 and categorise unit trusts in operation on or before January 1996 into performing and non-performing funds better than the CI01.

\section{Hypothesis}

The hypothesis tested is whether one of the four normal portfolio indices provided a better benchmark for unit trusts investing in the general equity sector of the JSE than the CI01. The correlation coefficients were tested at the 0.05 level of significance.

\section{Research methodology}

\section{Construction of the normal portfolio}

Three steps were used to construct the normal portfolios (Fabozzi, 1989) for the calculation of the indices. The first step was to define the 'investable universe' from which a fund manager could select stocks. The second was to select securities for inclusion into the normal portfolio and the third was to weight the securities.

This is shown schematically in Figure 1.

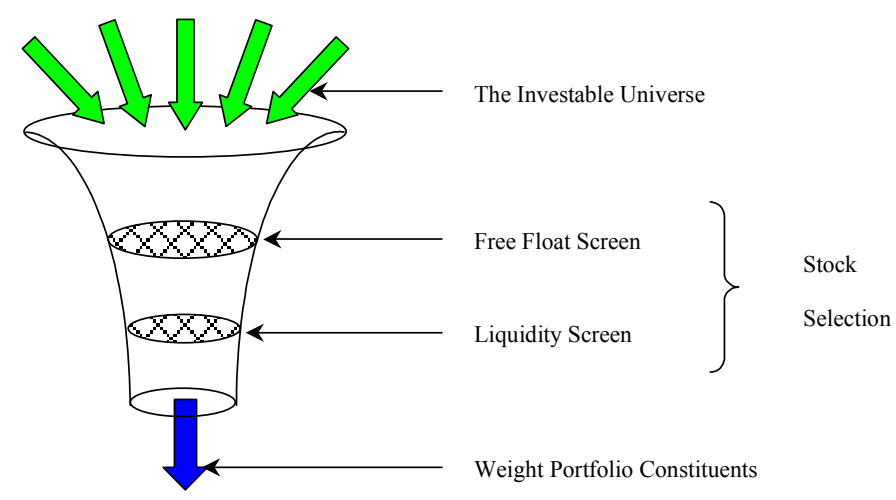

Figure 1: Development of a normal portfolio index

\section{Defining of the investable universe}

All stocks listed on the JSE were chosen to comprise the 'investable universe'. To avoid survivorship bias in the index, the normal portfolio was composed of all listed stocks at the date of the portfolio construction. 


\section{Stock selection}

The selection of portfolio constituents required the identification of the free float for each stock, calculation of the free float adjustment and determination of the liquidity of the stocks.

Shares in nominee accounts complicated the identification of free float. K-means cluster analysis was applied to nominee accounts and produced two categories of nominees. The nominees in the first category had a high variance of stock holdings and were defined as 'traders'. On the other hand, the nominees in the second category had a low variance and were defined as 'holders'. All the 'trader' accounts were then added to the stock's free float percentage.

Once the free float had been identification, the free float adjustment of each stock calculated according to the FTSE, MSCI or STOXX rules.

The liquidity of each stock was then determined using the three appropriate FTSE, MSCI, STOXX rules and a fourth rule using parts of these three sets of rules. For example, FTSE rules state that $0.5 \%$ of issued shares must be traded in five of the six months preceding a rebalancing of the index for a stock to be included in the index. It follows that if a stock had 2 million shares in issue and the free float adjustment was $50 \%$ then at least 5000 shares must trade in five of the preceding six months $(0.5 \%$ × 2 million $\times 50 \%=$ $5000)$.

\section{Weighting of index constituents}

Finally, the product of their market capitalisation and free float adjustment percentage were used to weight the portfolio constituents.

\section{Construction of normal portfolio indices}

Construction of the normal portfolio indices involved choosing a base index value and calculating changes to the index for each month. An index divisor was calculated in exactly the same manner as the CI01, except that the normal portfolio indices' index divisor was adjusted for free float and liquidity adjustments in addition to new corporate actions.

\section{Construction of optimum normal portfolio index}

The optimum normal portfolio index was constructed by developing new free float and liquidity rules. The new rules were chosen so that the index gave the highest possible cumulative return and correlation with the CI01 in order to smooth the transition to this index. This was achieved by excluding stocks with a free float lower $2 \%$ and adjusting the actual free float percentage to the next highest quartile in which it falls as shown in Figures 2 and 3. The liquidity rule excluded index constituents from the index if no shares had traded during the previous month.

The index was rebalanced annually for free float adjustments and monthly for liquidity changes.

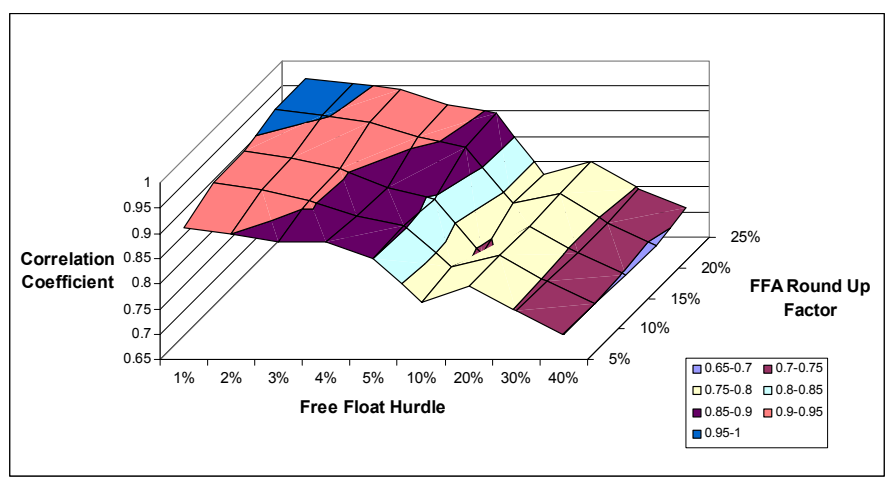

Figure 2: Variation of NPI (OPT) cumulative return

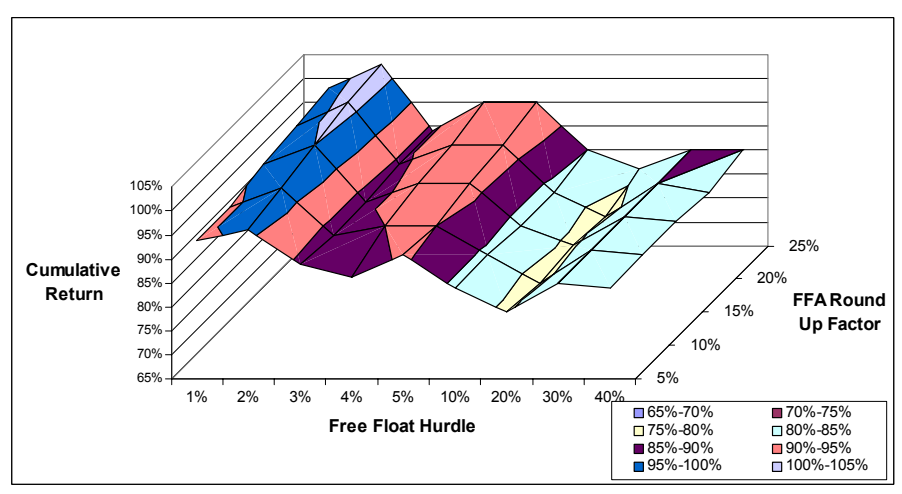

Figure 3: Variation of correlation between NPI (OPT) and CI01

\section{Answering the research question, establishing the proposition and testing the hypothesis}

The research question was investigated using the four characteristics of a good index (Francis, 1986).

The validity of the proposition depended on whether the normal portfolio indices over or under-performed the CI01 as measured by the Sharpe ratio. The risk free rate used was the average 3 month Johannesburg inter-bank banker's acceptance rate during the period January 1996 to December 2000. Unit trusts returns were calculated monthly by measuring the increase in the fund's sell-sell unit price less the fund fees and value added tax. Fees taken in account were the initial joining fee, annual management fee and compulsory charge. These were all converted from an annual to a monthly charge.

The Z- test for two correlation coefficients was used to test whether the correlation coefficients between each unit trust and the $\mathrm{CI} 01$ and unit trusts and the normal portfolio indices were significantly different (Kanji, 1993).

\section{Limitations}

The findings of the paper are limited in three ways.

- No attempt was made to verify the data gathered from INET, BFA Net and the JSE Bulletins. Where data was missing in a data series, interpolation was used to complete the series. 
- It was assumed that changes to the number of a company's issued shares took place at the financial year-end.

- The sample from the population of stocks from each sector used to calculate the free float percentage in nominee holdings was chosen to be proportional to the sector's representation on the JSE.

\section{Presentation and interpretation of results}

\section{Research question - suitability of screening rules}

The research question was investigated using the four criteria for an optimal index, as noted by Francis (1986).

\section{Sample size}

Each of the screening rules resulted in a different number of index constituents (see Figure 4). The lower bound of the number of index constituents is the ability to track market movements. The availability of computers means that there is now no limit to the number of constituents since indices are no longer calculated manually.

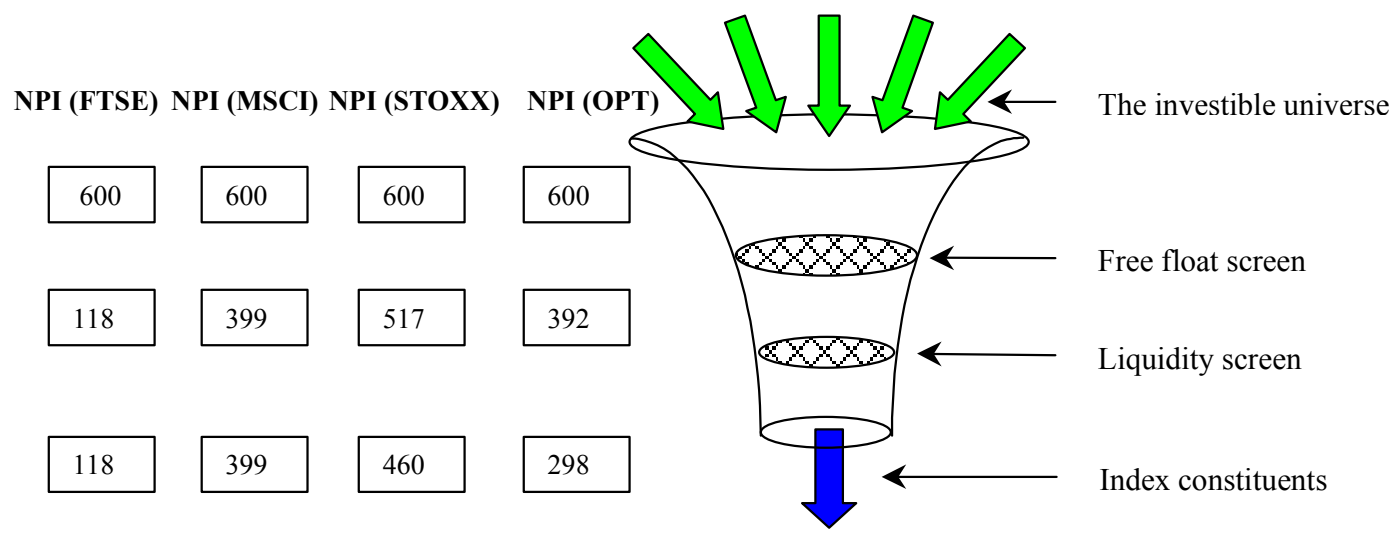

\# Stocks remaining at each filter level

Figure 4: Effect of screening rules reducing number of index constituents

The small number of index constituents for the FTSE screening rules $(20 \%$ of the 'investable universe') meant that it would not offer an accurate indication of market movements and would cause stock price volatility due to the 'index effect' (Garcia \& Gould, 1993). This occurs when the fund is re-balanced in order to track the index. However, the Standard and Poor Corporation (1989) found that the index effect caused only a small price boost (of $2 \%$ or less). The explanation was that demand for stock with a high free float was greater than for stock with a small free float, causing the former to rise and the latter to fall.

In SA, the Unit Trust Control Act No. 54 (1981) provides a lower bound for the number of index constituents. The Act restricts fund managers to holding a maximum of $5 \%$ of their portfolio in any one stock. Reducing the number of index constituents may therefore force fund managers to hold stocks they would not otherwise consider.

The other screening rules resulted in more index constituents, $(67 \%, 77 \%$ and $50 \%$ of the 'investable universe' respectively), and were therefore superior at measuring market movements.

\section{Representivity of population}

Against the needs to represent shares listed on the JSE in terms of stock market capitalisation size, sector and free float percentage, the results showed that the CI01 had a bias towards financial and industrial stocks, while the other indices all had a bias towards resources stocks. On the other hand, the results also showed that all indices exhibited the same trend in composition towards large, mid and small capitalization stocks.

In follows that stocks in the JSE's resources sector had a higher liquidity and free float than stocks in the financial and industrial sector. The fact that all normal portfolio indices resulted in a bias towards financial and industrial sector stocks will cause these indices to emphasise movements in the financial and industrial sectors as opposed to the resources sector and may produce very different index values to the CI01 in future. The similar spread of large, mid and small capitalisation stocks as the CI01 makes all four indices more acceptable.

\section{Weighting and convenience of units}

Figure 5 shows the effect of applying the screening rules to stocks listed on the JSE. As expected, the CI01 shows a large percentage of stocks with a low free float. The FTSE rules provided a large percentage of mid free float stocks, and consequently less index constituents because of the small number of mid free float stocks listed on the JSE. The MSCI index constituents are more balanced across all categories of free float adjustment, although there is a slight bias towards small and mid free float adjusted stocks. The STOXX index has a bias towards low free float adjusted 
stocks and the optimum normal portfolio index shows a bias towards mid free float adjusted stocks.

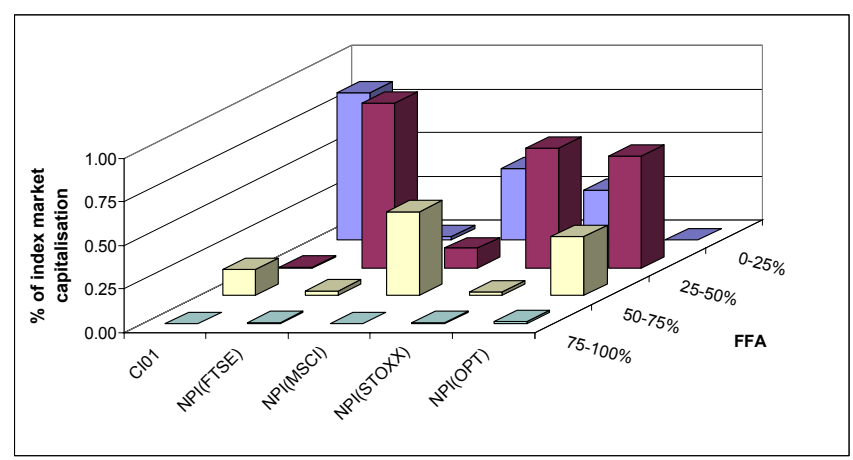

Figure 5: Analysis of CI01 and NP indices by FFA

The respective biases of the FTSE and STOXX rules towards mid and low free float stocks implied the development of a less that optimal index. In contrast, the MSCI and optimum normal portfolio rules resulted in an index with an improved spread of free float stocks.

All indices used units that were easy to comprehend and analyse.

\section{Proposition - Comparison between normal portfolio and $\mathrm{Cl} 01$ returns}

Figure 6 shows the Sharpe ratio for each index while Figure 7 gives their performance relative to the unit trusts. Together they demonstrate that the $\mathrm{CI} 01$ was the hardest of the indices to beat. It was followed by the optimum normal portfolio index that also had the desirable property of dividing the funds more evenly into performing and nonperforming funds. Since a good benchmark will divide the performance of funds as evenly as possible, the Sharpe measures indicated that the optimum normal portfolio index was a better benchmark for unit trusts than the CI01. The enhanced benchmark property of the free float index was evident from the fact that optimum normal portfolio index divided the unit trusts into performing and non-performing funds in the ratio 7:10 as opposed to $2: 15$ by the CI01.

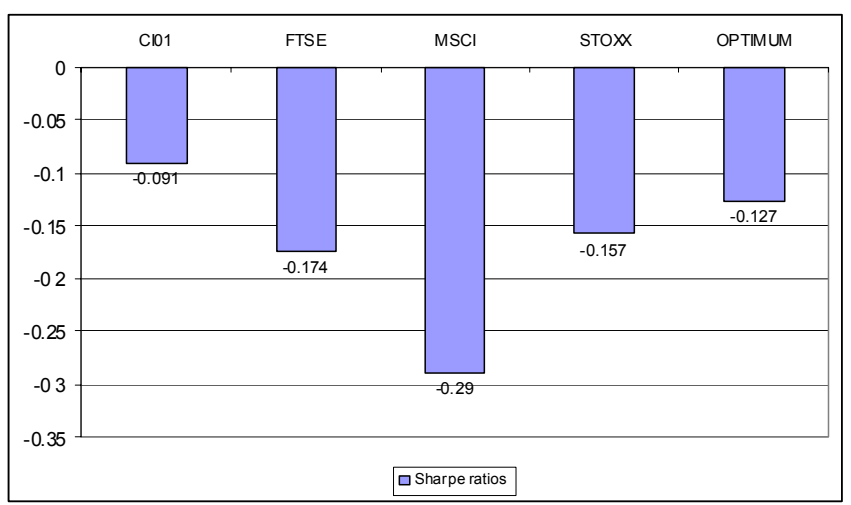

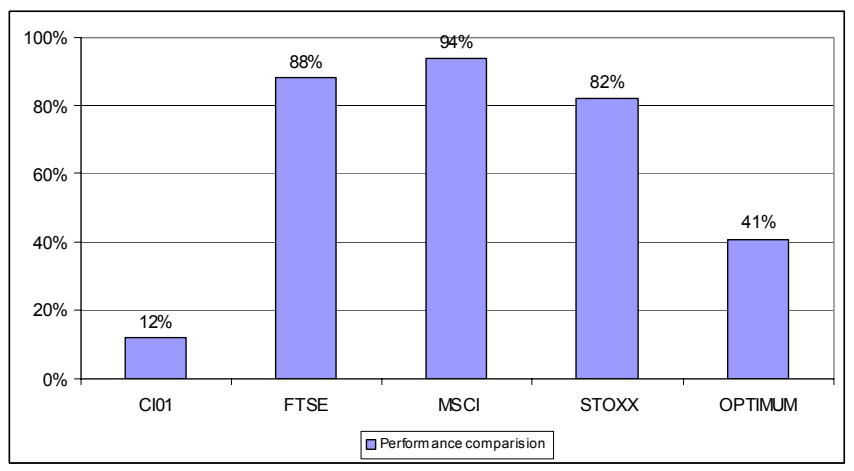

Figure 7: Percentage of unit trusts outperforming each index

The comparative cumulative returns of indices and the top, middle and bottom performing unit trusts over the period January 1996 to December 2000 are graphed in Figure 8. It shows that the CI01 out-performs all the free float indices and that the worst performing unit trust out-performs the free float index based on the MSCI rules.

One reason for the CI01 out-performing the other indices is that their relatively liquid free float constituents are more influenced by bull and bear runs because they are traded in both situations. (In contrast, the more tightly held stocks in the CI01 would not fluctuate as much during market turbulence). This is supported by the fact that the standard deviation of the monthly returns of all free float indices was greater than that of the $\mathrm{CIO} 1$ and that the CI01 fell less than the free float indices during the August 1998 market crash. Essinger \& Lowe (1997) noted that a fund might overperform an index because the fund has the ability to stock select and time the market. The August 1998 market crash illustrates this point. Of the funds in operation at the time, $46 \%$ fell less than optimum normal portfolio index during August, and between $71 \%$ and $96 \%$ of the funds outperformed the optimum normal portfolio index over the subsequent months as fund managers practiced market timing and stock selection.

Essinger \& Lowe (1997) also state that under-performance may be a result that a 'real life' portfolio might not be able to obtain new share issues at the index price at the time of the issue. This is similarly true for free float indices that do not include a stock until it has traded sufficient shares and achieved an acceptable liquidity. For instance, when Prism listed in October 1999 the price rose 43\% during October against $21 \%$ over November. Since the listing was $100 \%$ oversubscribed, not all investors benefited from the initial substantial returns.

The findings that unit trusts had a higher correlation with the CI01 than any of the normal portfolio indices and that the optimum normal portfolio index was a better benchmark than the CI01 are significant. Together they imply those stocks with a low liquidity and free float adversely affected investors trading on the JSE

Figure 6: Sharpe ratios 


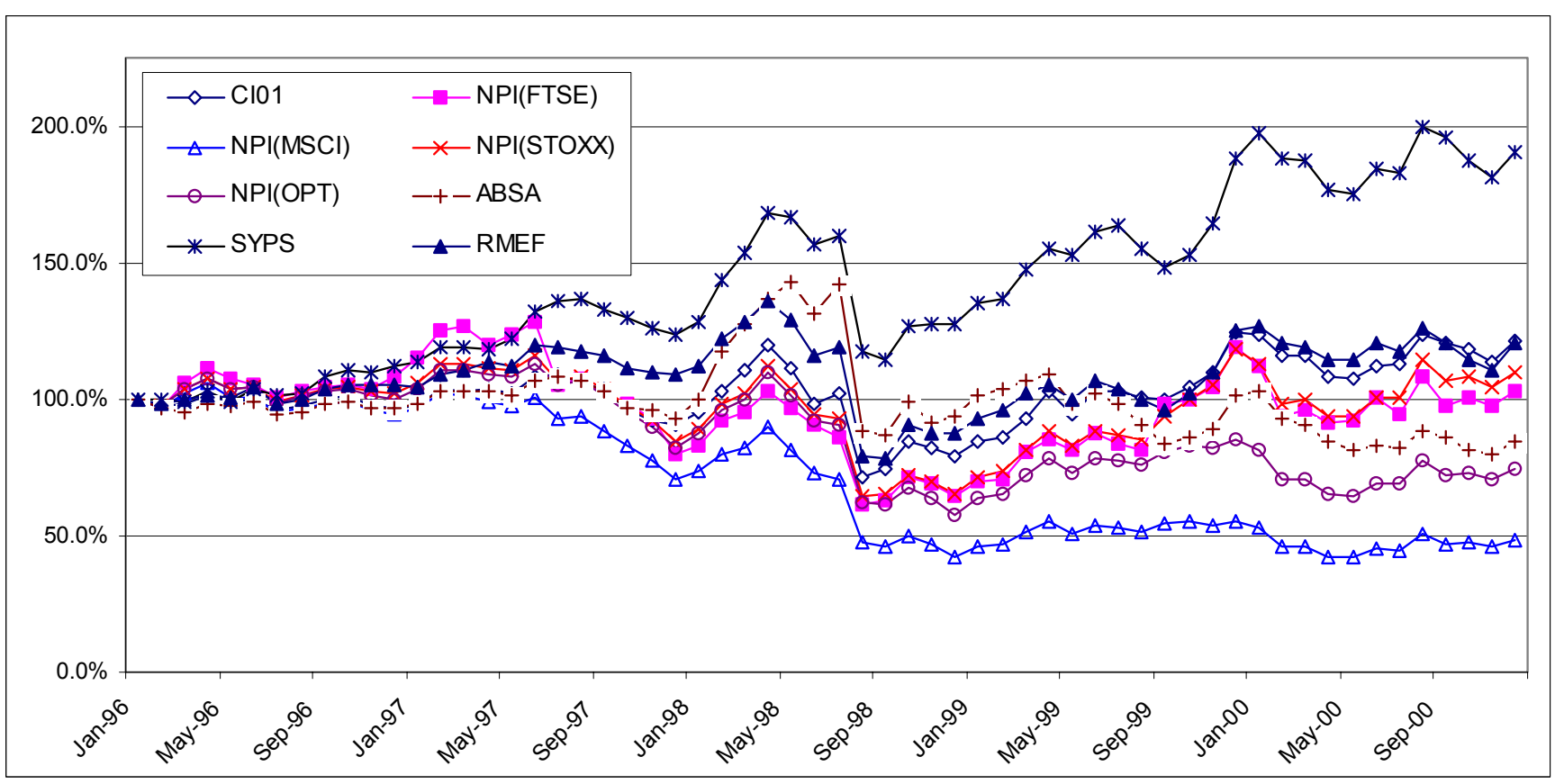

Figure 8: Comparative cumulative returns: January 1996 to December 2000 indices versus top, middle and bottom quartile unit trusts

Hypothesis - correlation between unit trusts and indices

The results of this test divided the unit trusts into three groups: Group 1 comprised unit trusts that correlated significantly with the normal portfolio indices, Group 2 comprised those that significantly correlated with the CI01, and unit trusts in Group 3 did not correlate significantly with either.

Details are shown in Table 1 . In every case more funds correlated with the CI01 than the respective normal portfolio index. However it can also be seen that the optimum normal portfolio index correlates more with the unit trusts than the other indices and is therefore the best of the free float indices.

\section{Table 1: Hypothesis Results}

\begin{tabular}{l|c|c|c|c}
\hline \# of UTs & $\begin{array}{c}\text { CI01 vs. } \\
\text { NPI (FTSE) }\end{array}$ & $\begin{array}{c}\text { CI01 vs. } \\
\text { NPI (MSCI) }\end{array}$ & $\begin{array}{c}\text { CI01 vs. } \\
\text { NPI (STOX } \\
\text { X) }\end{array}$ & $\begin{array}{c}\text { CI01 vs. } \\
\text { NPI (OPT) }\end{array}$ \\
\hline All funds & \multicolumn{5}{|c}{} \\
\hline Group 1 UTs & 0 & 0 & 0 & 0 \\
\hline Group 2 UTs & 37 & 21 & 22 & 10 \\
\hline Group 3 UTs & 4 & 20 & 19 & 31 \\
\hline Funds operating on or before 01/01/1996 & 0 \\
\hline Group 1 UTs & 0 & 0 & 0 & 4 \\
\hline Group 2 UTs & 17 & 10 & 10 & 13 \\
\hline Group 3 UTs & 0 & 7 & 7 & \\
\hline
\end{tabular}

The majority of unit trusts had a significantly higher correlation coefficient with the CI01 than all the normal portfolio indices. The fact that the majority of unit trusts correlated with the CI01 than the normal portfolio indices indicated that fund managers were using proxies in an attempt to track the CI01. Using only the results of the hypothesis test, the new screening rules rank above the STOXX, MSCI and FTSE rules.

\section{Conclusions}

The research demonstrated that investors trading stocks listed on the JSE suffered from free float and liquidity constraints in attempting to track the C101. The desirable characteristics required of an optimum normal portfolio index include that it represents the JSE without bias towards sectors, size of market capitalization, free float percentage and degree of liquidity. In addition the optimum index should correlate as highly as possible with the CI01 so that an easy transition is facilitated.

The problems can be addressed and the desirable characteristics obtained by introducing a new free float JSE index such as the optimum normal portfolio index developed and tested in the paper. However this new index will need to be based on rules customised for the JSE rather than applying existing British and American rules.

\section{References}

Bailey, J. V., Richards, T. M. \& Tierney, D. E. 1990. Current topics in investment management. New York: Harper Collins.

Birt, J. 2000. Global market indices gather steam. Reuters Magazine.

[http://about.reuters.com/magazine/julaug99/euro.htm] (Accessed 8 August 2000). 
Blitzer, D. M. 1995. 'Survivorship bias: Comment', Journal of Portfolio Management, Winter:102-104.

Cohen, J. B., Zinberg, E. D. \& Zeikel, A. 1987. Investment analysis and portfolio management. $5^{\text {th }}$ Ed., Illinois: Irwin.

Essinger, J. \& Lowe, D. 1997. The handbook of investment management. London: Pitman Publishing.

Fabozzi, J. F. 1989. Portfolio \& investment management. Chicago: Probus Publishing Company.

Financial Mail. 2001. Personal wealth weekly.

Francis, J. C. 1986. Investments: Analysis and management. New York: McGraw-Hill Book Company.

FTSE. 2000. Ground rules for the management of the FTSE All-World Index. Version 1.3 July 2000. [http://www.ftse.com/rules2/AllWorld.doc] (Accessed 8 August 2000).

Garcia, C. B. \& Gould, F. J. 1993. 'Survivorship bias', Journal of Portfolio Management, Spring:52-56.

Gaymans, J. 2001. HSBC South African Index. Derivatives analysts report. Johannesburg. Equities Research Department.

Gleason, D. 1998. 'The dangerous art of window dressing', Financial Mail, October 30:54-55.

Good, W. R. 1983. 'Measuring performance', Financial Analysts Journal, May-June 19-23.

Good, W. R. 1984. 'Accountability for pension fund performance', Financial Analysts Journal, January-February $39-42$.

Grinold, R. C. 1992. 'Are benchmark portfolios efficient?' Journal of Portfolio Management, Fall 34-40.

Ippolito, R.A. 1992. 'Consumer reaction to measures of poor quality: Evidence from the Mutual Fund Industry', Journal of Law and Economics, 35(1):45-70.

JSE. 2000.2 JSE/Actuaries Indices. [http://www.jse.co.za/indices/actuaries_indices/index.html] (Accessed 8 August 2000).

Kanji, G. K. 1993. 100 Statistical tests. London: Sage Publications Ltd.
Kritzman, M. 1987. 'How to build a normal portfolio in three easy steps', Journal of Portfolio Management, Summer 21-23.

Lakonishok, J., Shleifer, A., Thaler, R. \& Vishny, R. 1991. 'Window dressing by pension fund managers', American Economic Review, 81:227-231.

Luck, C. G. 1995. 'Style in indexes and benchmarks'. In Performance evaluation, benchmarks, and attribution analysis. ICFA Continuing Education, Association for Investment Management and Research.

Lummer, S. L. 1995. 'U.S. equity indexes as benchmarks'. In Performance evaluation, benchmarks, and attribution analysis. ICFA Continuing Education, Association for Investment Management and Research.

Masters, S. J. 1998. 'The problem with emerging market indexes', Journal of Portfolio Management, Winter 93-103.

McNulty, A. 2001. Free float indices may offer a more honest view of the JSE returns. Financial Mail, 19 January: 46.

MSCI. 2000. MSCI free float adjustment and increase in target market representation. [http://www.msci.com/method] (Accessed 15 February 2001).

Mossavar-Rahmani, S. 1987. 'Customized benchmarks in structured management', Journal of Portfolio Management, Summer:65-68.

Moneymax. 2000. Structure: Plexus Unit Trust Indices. [http://plexus.moneymax.co.za/investments/unit_trusts/ut_in dices/struct.asp] (Accessed 8 August 2000).

Roll, R. 1978. 'Ambiguity when performance is measured by the securities market line', Journal of Finance, 33:10511069.

Standard and Poor Corporation. 1989. 'Companies added to the S\&P 500 - The 'Price effect'.In The S\&P 5001989 Directory. New York: Standard and Poor's Corporation.

STOXX. 2000. Dow Jones Stoxx Index Guide, Version 6.0. Zurich, Switzerlandh: Stoxx Limited.

Tucker A. L., Becker, K. G., Isimbubi, M.J. \& Ogden, J. P. 1994. Contemporary portfolio theory and risk management, $1^{\text {st }}$ Edition. New York: West Publishing Company.

Government Gazette, No. 7760, 1981. Unit Trust Control Act No. 54.

Wood, S. 1999. 'Window dressing: Wiping the window clean', Financial Mail, 2 July 1999:55. 
